\title{
First Record of the Genus Pseudodryinus (Hymenoptera: Dryinidae: Dryininae) in Korea
}

\author{
Chang-Jun Kim, Gang-Won Choi, Jong-Wook Lee* \\ Department of Life Sciences, Yeungnam University, Gyeongsan 712-749, Korea
}

\begin{abstract}
The genus Pseudodryinus Olmi, 1989 belonging to the subfamily Dryininae has been reported for the first time in Korea, base on the discovery Pseudodryinus shihoae Mita, 2009. We have provided a redescription and photographs of the diagnostic characteristics of the species.
\end{abstract}

Keywords: Pseudodryinus shihoae, Dryininae, Dryinidae, Korea

\section{INTRODUCTION}

The subfamily Dryininae Kieffer, 1906 is a moderate dryinid group comprising seven genera: Thaumatodryinus Perkins, 1905; Dryinus Latreille, 1804; Megadryinus Richards, 1953; Cretodryinus Ponomarenko, 1975; Gonadryinus Olmi, 1989; Pseudodryinus Olmi, 1989 and Harpactosphecion Ponomarenko, 1975 (He and Xu, 2002). Of those, Pseudodryinus is a small genus with seven extant species, only one of which has been found in the Palaearctic region, and none yet reported in Korea. All Pseudodryinus have palp formulas of 5/3, $4 / 3$, or $3 / 2$, and a single subapical tooth on the enlarged claw (Mita, 2009).

Herein we report the Korean occurrence of Pseudodryinus shihoae Mita, 2009 for the first time. The genus is also new to Korea. We provide redescription, photographs of diagnostic characteristics, and keys to the known three Korean species of Dryininae.

The morphological terminologies used in this study followed those of Olmi $(1984,1994,1999)$. Photographs were captured with an AxioCam MRc5 camera through a stereomicroscope (Stemi SV 11 Apo; Carl Zeiss, Göttingen, Germany), processed with AxioVision40AC software (Carl Zeiss), and optimized with an $i$-delta imaging system.

Abbreviations for type depositories, type information, collecting method, and descriptions are as follows: ELKU, Entomological Laboratory, Kyushu University, Fukuoka, Japan; YNUE, Department of Life Sciences, Yeungnam University,
Gyeongsan, Korea; TD, type depository; TL, type locality; TS, type species; MT, malaise trap; POL, distance between the inner edges of the two lateral ocelli; OL, distance between the inner edges of a lateral ocellus and median ocellus; OOL, distance from the outer edge of a lateral ocellus to the compound eye; OPL, distance from the posterior edge of a lateral ocellus to the occipital carina.

\section{SYSTEMATIC ACCOUNTS}

Order Hymenoptera

Superfamily Chrysidoidea Day, 1977

Family Dryinidae Haliday, 1833

$1 *$ Subfamily Dryininae Kieffer, 1906

2*Genus Pseudodryinus Olmi, 1989

Pseudodryinus Olmi, 1989: 365. TS: Pseudodryinus townesi (Olmi, 1984).

Key to the Korean genus and species of subfamily Dryininae

1. Maxillary palps 5-segmented …...(Genus Pseudodryinus) 3*Pseudodryinus shihoae Mita, 2009

- Maxillary palps 6-segmented ........... ( $\left({ }^{*}\right.$ Genus Dryinus $)$

2. Body entirely black. Enlarged claw with a row of 13 lamellae. Forewing with 2 dark transverse bands

5*Dryinus baegamensis Lee and Kim, 2010

(c) This is an Open Access article distributed under the terms of the Creative Commons Attribution Non-Commercial License (http://creativecommons.org/ licenses/by-nc/3.0/) which permits unrestricted non-commercial use, distribution, and reproduction in any medium, provided the original work is properly cited.

*To whom correspondence should be addressed

Tel: 82-53-810-2376, Fax: 82-53-811-2376

E-mail: jwlee1@ynu.ac.kr

Korean name: ${ }^{2 *}$ 집게벌아과 (신칭), ${ }^{2 *}$ 어리집게벌속 (신칭), ${ }^{3 *}$ 일본어리집 게벌 (신칭), ${ }^{4 *}$ 집게벌속 (신칭), ${ }^{5 *}$ 백암집 게벌 (신칭) 

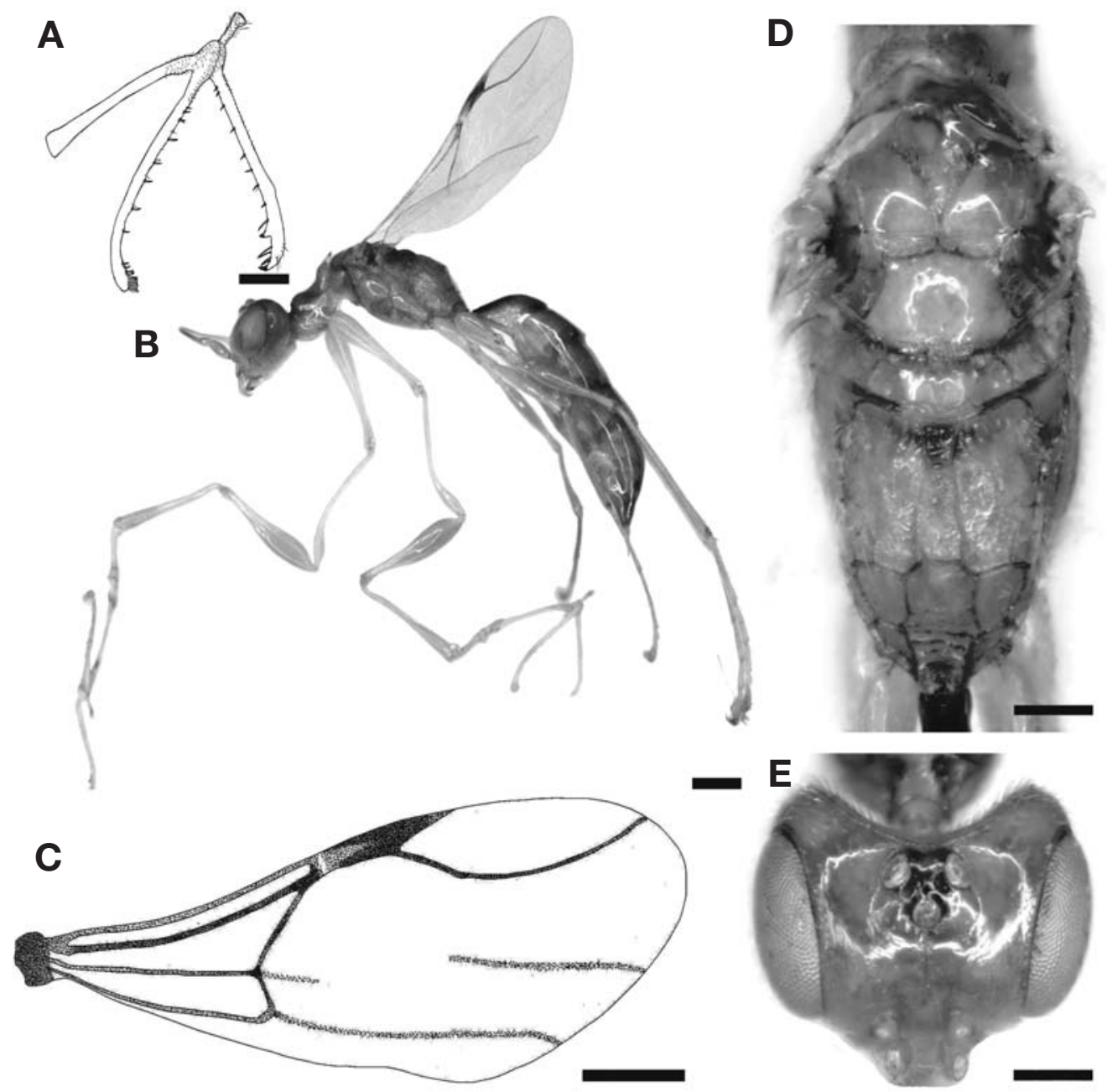

Fig. 1. Pseudodryinus shihoae Mita, 2009, female. A, Chela; B, Habitus in lateral view; C, Forewing; $D$, Thorax in dorsal view; $E$, Head in Dorsal view. Scale bars: $A, E=0.1 \mathrm{~mm}, B, C=0.5 \mathrm{~mm}, D=0.2 \mathrm{~mm}$.

- Body almost entirely testaceous, except petiole black. Enlarged claw with a row of 11 lamellae. Forewing without dark transverse band

$1 *$ Dryinus koreanus (Moczar), 1983

\section{Pseudodryinus shihoae Mita, 2009 (Fig. 1A-E)}

Pseudodryinus shihoae Mita, 2009: 45-56. Type: female; TL: Western Honshu, Japan; TD: ELKU.

Materials examined. Korea: 1 우, Gangwon-do, Chuncheonsi, Dong-myeon, Jinae-ri, 16-22 Aug 2005 (MT), Jang SJ [YNUE]; 1 우, Gyeonggi-do, Anyang-si, Manan-gu, Kwanag, 8 Aug-5 Sep 2008 (MT), Lim JO [YNUE]; Japan: 1 우, Miyama-no-Taki, Kure-Shi, Hiroshima Pref., 22-23 Aug 2002
(MT) (Shiho Arai leg.) (Holo-type) [ELKU].

Description. Female: Body length 4.3-4.4 mm. Forewing length 3.0-3.1 mm.

Head. Broader than the thorax; flat, smooth and shiny, with minute punctures and setae. Frontal line distinct. Occipital carina incomplete, absent near madibular base. POL: 4; OL: 2; OOL: 7.5; OPL: 1 (Fig. 1E). Mandible with four teeth of similar size. Antennae filiform; length of antennal segments from scape to 8 th flagella segments as following proportionate as: $9: 6: 41: 19: 14: 13: 8: 8: 8: 9$.

Thorax. Pronotum crossed by 2 transversal impressions and covered with short hairs, shiny and smooth; pronotal tubercles reaching tegula. Scutum and scutellum shiny, smooth and covered with short hairs; notaulices converging posteri-

Korean name: ${ }^{1 *}$ 북방고려집 게벌 (신칭) 
orly and touching each other (Fig. 1D).

Metanotum about $0.33 \times$ as long as scutum, shiny, smooth and covered with short hairs. Meso-metapleura suture distinct; mesopleuron and metapleuron smooth. Dorsal surface of propodeum laterally $0.66 \times$ as long as posterior surface, with two median longitudinal keels and covered with short hairs; posterior surface of propodeum with two distinctly longitudinal keels and transverse keels; surface between longitudinal keels transversely striate and covered with very short hair.

Wing. Fully winged. Fore and hind wing hyaline without dark transverse band; covered with testaceous setae; forewing distal part of stigmal vein about $2.6 \times$ as long as proximal part and reaching distal apex (Fig. 1C).

Legs. Inner margin of enlarged claw with rows of 9 lamellae and 4 lamellae between subapical tooth and distal apex (Fig. 1A). Fore tarsal segments in length as following proportionate as: $5.0: 1.0: 2.5: 10.0: 15.0$; fifth segments of fore tarsus with two rows of 9 lamellae in inner margin; distal apex with a group of 13 lamellae; rudimentary claw present. Fore and mid tibia with 1 spur; hind tibia with 2 spurs, inner spur longer than outer spur.

Abdomen. Smooth and shiny, with rarely short hairs.

Color. Head and body testaceous; ocellar region and dorsal surface of propodeum anteriorly dark brown; teeth of mandible brown to reddish; antennal scape, pedicel and 1th-4th flagella segments testaceous, 7th-10th segments whitish; legs yellow, with femora testaceous; anterior dorsal surface of propodeum with dark brown spot; petiole dark brown; anterior marginal dorsal surfaces of entire terga dark brown; hypopygium dark brown.

Male: Unknown.
Host records. Unknown.

Distributions. Korea (new record) and Japan.

\section{ACKNOWLEDGEMENTS}

We thank to Dr. Jong-Ok Lim (Korea National Arboretum) for providing the valuable specimens. We also thank to Prof. Osamu Tadauchi (Entomological Laboratory of Kyushu University, Japan) and Dr. Toshiharu Mita (Laboratory of Entomology, Faculty of Agriculture, Tokyo University, Japan) of for providing type speciemen. This study was supported by the Korean Institute of Environmental Science and Technology, Ministry of Environment grant (KIEST 052-081213072).

\section{REFERENCES}

He J, Xu Z, 2002. Hymenoptera Dryinidae. Fauna Sinica, Vol. 29. Science Press, Beijing, pp. 242-244.

Mita T, 2009. A taxonomic study of the Dryininae (Hymenoptera: Dryinidae) of Japan, with description of a new species of Pseudodryinus. Zootaxa, 2168:45-56.

Olmi M, 1984. A revision of the Dryinidae (Hymenoptera). Memoirs of the American Entomological Institute, 37:1-1913.

Olmi M, 1994. The Dryinidae and Embolemidae (Hymenoptera: Chrysidoidea) of Fennoscandia and Denmark. Fauna Entomologica Scandinavica, 30:1-100.

Olmi M, 1999. Hymenoptera Dryinidae-Embolemidae. Fauna d'Italia. Vol. 37. Edizioni Calderini, Bologna, pp. 1-425.

Received May 4, 2011 Accepted June 29, 2011 